\title{
DEFLECTION OF STEEL REINFORCED CONCRETE BEAM PRESTRESSED WITH CFRP BAR
}

Carbon Fiber Reinforced polymer (CFRP) bars are weak in yielding property which results in sudden failure of structure at failure load. Inclusion of non-pretensioned steel reinforcement in the tension side of CFRP based prestressed concrete beam will balance the yielding requirements of member and it will show the definite crack failure pattern before failure. Experimental investigation has been carried out to study the deflection behavior of partially prestressed beam. Experimental works includes four beam specimens stressed by varying degree of prestressing. The Partial Prestressing Ratio (PPR) of specimen is considered for experimental works in the range of 0.6 to 0.8 . A new deflection model is recommended in the present study considering the strain contribution of CFRP bar and steel reinforcement for the fully bonded member. New deflection model converges to experimental results with the error of less than $5 \%$.

Keywords: Cracked Moment of Inertia, Deformability, Effective Moment of Inertia, Neutral axis, Partial Prestressig Ratio, Yielding point

\section{Introduction}

Damage of structure due to corrosion of steel prestressed concrete member (PSC) is significantly influencing the performance of the member. There are various environmental parameters influencing the corrosion of steel tendons such as chloride, freezing-and-thawing, and temperature. From various research an alternate material for steel was carried out during 1950 and proposed Fiber Reinforced Polymer (FRP) material. FRP bars consist of unidirectional fibers embedded in a matrix resin. The epoxy resin is mostly considered for the matrix resin. FRP bars are widely used in corrosive vulnerable areas due to its non-corrosive, high strength to weight proportion and fatigue properties. The usage of FRP was limited due to its non-ductile behavior. Dolan, et al. [1] stated that the strain ratio at ultimate stage to service stage of the FRP tendon is less as compared to steel tendon. Hence, it leads to increase in deflection in a faster rate than steel based PSC member. So the deflection behaviour of FRP based PSC beam does not resemble as steel based PSC. In order to improve the yielding performance of member, CFRP PSC member is designed as a partial prestrssed beam by including steel reinforcement which in turn results in improvements of load deflection pattern of member. Hence the pattern of load vs deflection of member is based on the partial prestressing ratio. The term partial prestressing ratio (PPR) shall be defined as ratio of prestressing material resistance force to the total material resistance force due to prestressing material and non-pretensioned steel. In this article an experimental investigation is carried out to study the deflection behavior of partially prestressedconcrete (PPSC) beam for the PPR range of 0.6 to 0.8 .

Fang, et al. [2] stated that the moment curvature of beam follows tri-linear pattern as compared to bilinear pattern of conventional CFRP PSC beam due to the inclusion of non-pretensioned steel. The moment of curvature of member is linearly varying with respect to applied load up to first crack stage. Further increase of load after first crack leads to loosen its stiffness and as a result the moment of curvature becomes non-linear. The pattern of moment of curvature non-linearity as shown in Fig. 1 depends on strain after decompression on CFRP bar and strain on non- pretensioned steel bar. Further increase of load up to failure of beam leads to the possibility of either CFRP or steel reinforcement reaches permissible strain earlier than one another. If the strain on CFRP bar reaches permissible strain limit earlier than permissible yield strain of steel, it result in rupture of CFRP bar and it leads to drop of moment of curvature and continued further until steel reaches to permissible strain. This behavior is similar to conventional steel prestressed beam. Alternatively, if the steel reaches permissible yield strain earlier than CFRP bar leads to change of moment of curvature pattern from the point of steel yielding. The non-linear behavior of deflection curve as shown in Fig. 1 up to steel yielding point is contributed by CFRP bar and steel. Beyond the steel strain limit, the strain on steel only increases for further increase in stress on member wherein CFRP beam continuously contribute for the moment of curvature 
effect until the failure for the tension controlled member. The deflection of concrete member at serviceability stage shall be calculated by considering the stiffness of concrete member Pre and post cracking of concrete and the shift of eccentricity of member result in increase in prestressing force. The mid span deflection $(\Delta)$ for the two point loading of simply supported beam shall be calculated considering the following equation.

\section{$\Delta=$ Deflection under loading $\left(\Delta_{1}\right)+$ Deflection due}

to self - weight $\left(\Delta_{2}\right)$ - Deflection due to prestressing force

$$
\begin{gathered}
\Delta_{1}=\frac{M_{\text {Live }}\left(3 L^{2}-4 a^{2}\right)}{24 E_{c} I_{\text {eff }}}+\frac{5 M_{D} L^{2}}{48 E_{c} I_{\text {eff }}}-\frac{P\left(d_{p}-Y_{\text {eff }}\right) L^{2}}{8 E_{c} I_{\text {eff }}} \\
\Delta_{2}=\frac{5 M_{D} L^{2}}{48 E_{c} I_{g}}-\frac{P\left(d_{p}-Y_{g}\right) L^{2}}{8 E_{c} I_{g}}
\end{gathered}
$$

Where $M_{\text {live }}$ is applied moment due to live load, $L$ is effective span of member, a is point load location from nearer support, $E_{c}$, is modulus of elasticity of concrete, $I_{\text {eff }}$ is effective moment of inertia of concrete, $M_{D}$ is Moment due to its self-weight of member, $d_{p}$ is effective depth of member with respect to centroid of prestressing bar and $Y_{\text {eff }}$ is effective neutral axis distance from extreme compression fiber of beam.

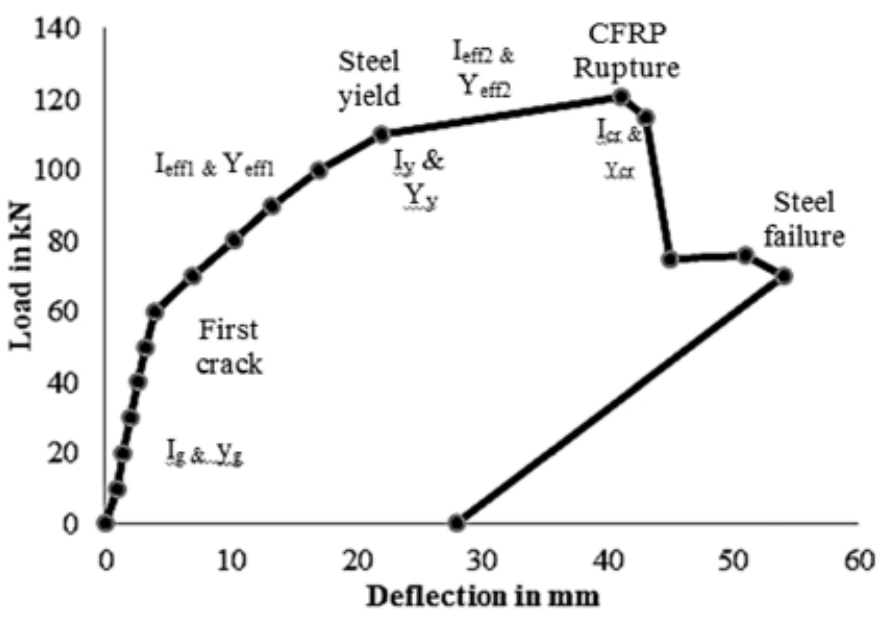

Fig. 1. Idealized load deflection curve for PPR less than one

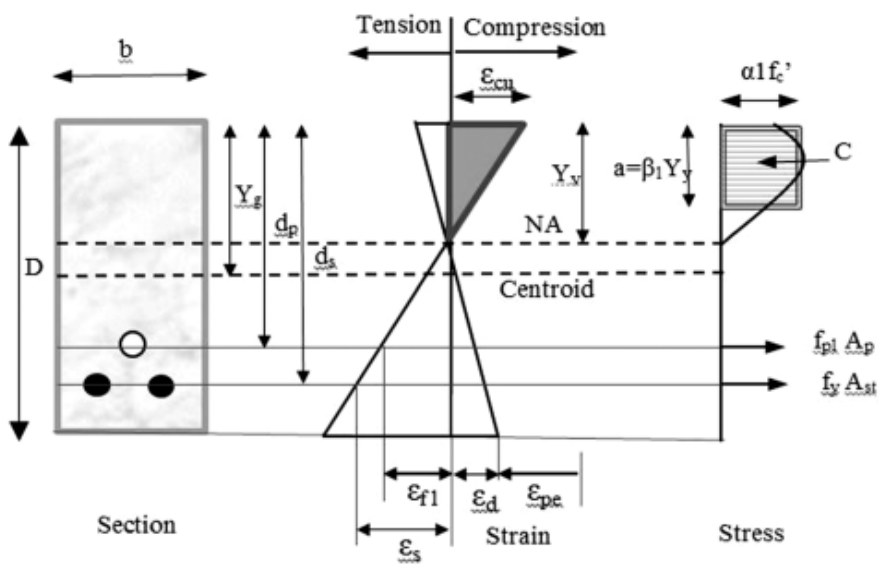

Fig. 2. Stress strain curve at steel yield point

\subsection{Moment of Inertia of concrete member}

Shunji Inomata [3] stated that the pattern of deflection curve changes as shown in Fig. 1 with respect to relative stiffness of member at various stage of loading. The moment of inertia of concrete for the member is gross moment of inertia $\left(I_{g}\right)$ upto first crack stage. Once the crack develops, the moment of inertia of concrete member reduces. Fang Zhietal., [2] stated that, the pattern of reduction rate of moment of inertia of tension controlled member shall be idealized as bilinear curve after first crack based on the steel yield point as occurred earlier than rupture of CFRP prestressing bar. The rate of change of moment of inertia termed as effective moment of inertia $\left(I_{\text {eff } 1}\right)$ changes from gross moment of inertia $\left(I_{g}\right)$ tomoment of inertia at steel yield point $\left(I_{y}\right)$ is with respect to combined influence of CFRP bar strain $\left(\varepsilon_{f}\right)$ after decompressed strain and strain of steel reinforcement $\left(\varepsilon_{s}\right)$. The residual strain $\left(\varepsilon_{f}\right)$ shall be measured by deducting the effective prestressing strain $\left(\varepsilon_{p e}\right)$ and decompressed strain $\left(\varepsilon_{d}\right)$ in the ultimate strain of CFRPbar $\left(\varepsilon_{p u}\right)$. The Fig. 2 shows the stress strain behavior of rectangular section partially prestressed with CFRP bar and reinforced with non-tensioned steel bar at the stage of steel yielding earlier than rupture of CFRP bar. The moment of inertia at steel yield point $\left(I_{y}\right)$ shall be calculated based on the stress strain of section at steel yield point as shown in Fig. 2.

By equating strain by similar triangle as shown in Fig. 2, it shall be written as

$$
\frac{\varepsilon_{s}}{\left(d_{s-} Y_{y}\right)}=\frac{\varepsilon_{c}}{Y_{y}}
$$

By rewriting equating (3), the equivalent compressive stress $\alpha_{1} f c^{\prime}$ shall be calculated.

$$
\propto_{1} f_{c}^{\prime}=\frac{E_{c} f_{y} Y_{y}}{E_{s}\left(d_{s-} Y_{y}\right)}
$$

The compressive and tensile force on beam section shall be calculated as area of stress block as shown in Fig. 2.

Compressive force

$$
\begin{aligned}
& \mathrm{C}=\alpha_{1} f c^{\prime} \beta_{1} Y_{y} b \\
& T=A_{p} f_{1 p}+A_{s t} f_{y}
\end{aligned}
$$

The tensile stress on CFRP bar at steel yield point $\left(f_{1 p}\right)$ shall be calculated by strain on CFRP bar by equating similar triangle as shown in Fig. 2.

$$
f_{1 p}=f_{p e}+E_{p}\left(\frac{\varepsilon_{s}}{\left(d_{s}-Y_{y}\right)}\right)\left(d_{p}-Y_{y}\right)
$$

Where $\varepsilon_{c}$ compression strain on concrete at extreme compression fiber, $d_{s}$ is is effective depth of member with steel reinforcement, $Y_{y}$ is neutral axis distance from extreme compression fiber at steel yielding point, $\beta_{1}$ is stress block coefficient with respect to concrete grade, $\alpha_{1} f_{c^{\prime}}$ is compression stress at extreme compression fiber, $\mathrm{b}$ is breadth of member, $A_{p}$ area of CFRP bar, $f_{p e}$ effective stress on CFRP bar, $f_{y}$ yield stress of steel reinforcement, $A_{s t}$ area of steel reinforcement, $E_{p}$ youngs modulus of CFRP bar and $E_{s}$ youngs modulus of steel reinforcement. 
By equating equation (5) \& (6) the neutral axis distance $\left(Y_{y}\right)$ at steel yield point shall be calculated. In addition the moment of inertia $I_{y}$ at steel yield point shall be derived from basic bending equations.

$$
I_{y}=\frac{M_{\text {at steel yield point }}}{E_{c} \phi}
$$

From stress strain curve as shown in Fig. 2 the moment curvature $(\phi)$ shall be derived.

$$
\phi=\frac{\varepsilon_{s}}{\left(d_{s-} Y_{y}\right)}
$$

The shift of effective moment of inertia $\left(I_{\text {eff } 1}\right)$ follows Branson [4] equation.

$$
I_{e f f 1}=\left(\frac{M_{c r}}{M_{a}}\right)^{3} I_{g}+\left(1-\left(\frac{M_{c r}}{M_{a}}\right)^{3}\right) I_{y}
$$

Where $M_{c r}$ is moment of resistance at first crack stage and $M_{a}$ is applied moment on beam.

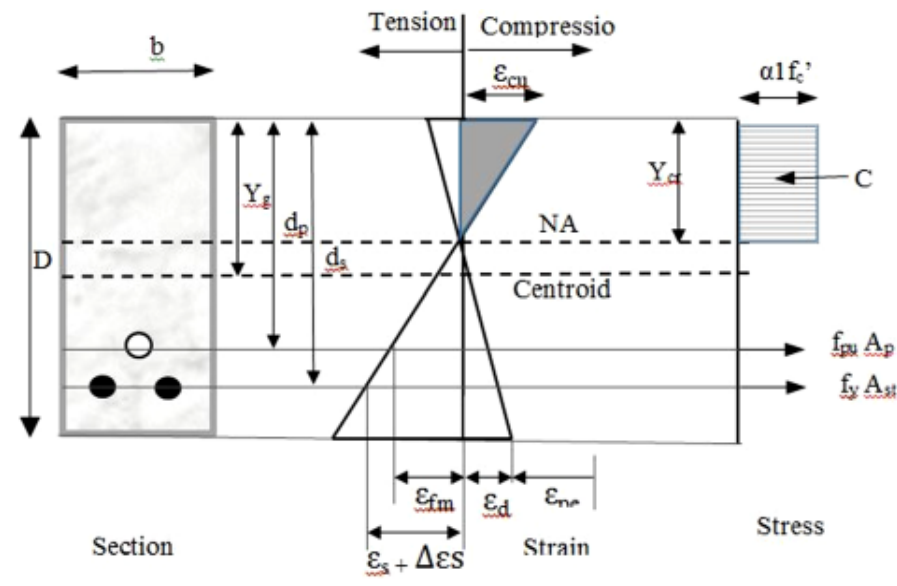

Fig. 3. Stress strain curve transformed section

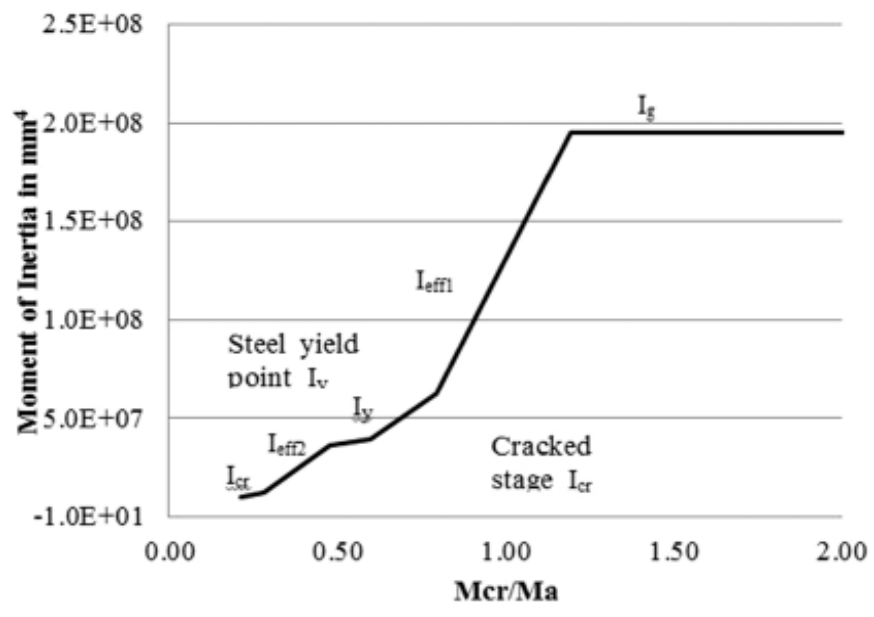

Fig. 4. Effective moment of inertia curve

Further increase of load on member leads to increase in stress on CFRP bar only due to the stress on steel reaches yield limit and only strain on steel along increases without absorbing additional load. At rupture stage of prestressed CFRP bar, the member stress strain reaches to fully cracked and shall be idealized as transformed section as shown in Fig. 3. The cracked moment of inertia $\left(I_{c r}\right)$ shall be calculated from basic principle of taking moment about neutral axis.

$$
\begin{aligned}
I_{c r}= & \frac{b Y_{c r}^{3}}{3}+m_{p} f_{p u} A_{p}\left(d_{p}-Y_{c r}\right)^{2}+ \\
& +m_{s} f_{y} A_{s t}\left(d_{s}-Y_{c r}\right)^{2}
\end{aligned}
$$

Where $Y_{c r}$ is neutral axis distance from extreme compression fiber at ultimate load stage, $m_{p}$ is modular ratio of modulus of elasticity of $\operatorname{CFRP}\left(E_{p}\right)$ and concrete $\left(E_{c}\right), m_{s}$ is modular ratio of modulus of elasticity of steel $\left(E_{s}\right)$ and concrete $\left(E_{c}\right)$.

The load deflection curve pattern changes further from steel yield point to upto failure stage as shown in Fig. 1. Natalie Sami Rizkalla [5] stated that, the rate of change of effective moment of inertia $I_{e f f 2}$ is changing with respect to deformability behavior CFRP and yielding behavior of steel. The rate of change of moment of inertia $I_{\text {eff } 2}$ changes from moment of inertia at steel yield point $\left(\mathrm{I}_{\mathrm{y}}\right)$ to moment of inertia at cracked stage $\left(I_{c r}\right)$ as shown in Fig. 4 shall be calculated based on basic Branson [4] equation.

$$
I_{e f f 2}=\left(\frac{M_{y}}{M_{a}}\right)^{3} I_{y}+\left(1-\left(\frac{M_{y}}{M_{a}}\right)^{3}\right) I_{c r}
$$

Where $M_{y}$ moment of resistance at steel yield point.

\subsection{Effective shift of neutral axis distance}

Branson \&Trost [6] and Tadros, et al. [7] predicted that prestressing eccentricity with respect to neutral axis is increasing due to shift of neutral axis during its cracking stage The effect of neutral axis shift is non-linear due to the tension stiffening effect of concrete and prestressing. This leads to an increase in prestressing moment which reduces the deflection rate of increases. The rate of shift of neutral axis curve is resembling as like effective moment of inertia shift curve as shown in Fig. 4. The shift of effective neutral axis distance upto steel yield point is $Y_{e f f 1}$ and then it is shifting to $Y_{e f f 2}$ curve upto fully cracked stage. The $Y_{\text {eff } 1} \& Y_{\text {eff } 2}$ shall be calculated based on the Branson [4] method as similar like moment of inertia calculations. ACI 440-4R [8] \& Abdulrahman [9] recommended the shift of neutral axis distance equation by modifying Branson [4] method with a two power curve considering the CFRP bar deformability behaviour.

$$
\begin{aligned}
& Y_{\text {eff } 1}=\left(\frac{M_{c r}}{M_{a}}\right)^{2} Y_{g}+\left(1-\left(\frac{M_{c r}}{M_{a}}\right)^{2}\right) Y_{y} \\
& Y_{\text {eff } 2}=\left(\frac{M_{y}}{M_{a}}\right)^{2} Y_{y}+\left(1-\left(\frac{M_{y}}{M_{a}}\right)^{2}\right) Y_{c r}
\end{aligned}
$$




\section{Experimental works}

Four numbers of beam specimen considered for prestressed beam using CFRP bar and reinforced with non-pretensioned reinforcement steel at tension side of beam. The degree of prestressing on CFRP bar is varied to $37 \%, 52 \%, 63 \%$ and $68 \%$ to study the behavior of member. The number and position of CFRP bar also varied to study the behaviour of beam with different conditions. Good bonded condition of prestressing bar with non pretensioned steel at tension side is designed for experimental works. The beam specimen configurations adopted for experimental works are shown in Fig. 7. The term CPB1-2H-0.63 means "CFRP partially prestressed - specimen number - Number of prestressed bar, bar positioned Horizontally $(\mathrm{H})$ or Vertically $(\mathrm{V})$ and the last term is Degree of effective prestressing in fraction. Simply supported beam with two point load is considered and the testing as shown in Fig. 5. The beam specimen is designed as tension controlled member to study the rupture failure of CFRP bar. Shear links of 2 legged $8 \mathrm{~mm}$ dia bar of $150 \mathrm{~mm}$ spacing designed to resist shear failure of member during testing. The strain gauge strip stacked on the surface of CFRP bar to measure the prestressing strain. Three dial gauges mounted at bottom of beam as shown in Fig.5 to measure the deflections during testing. Grid formation marked at the surface of $1 \mathrm{~m}$ mid span zone of beam and pellet fixed at each grid node to measure the strain at grid node in the mid span zone. The deflection is measured for every increment of load.

Concrete grade of M50 is considered and it is confirmed by trial mix test results as shown in Table 1. Nine numbers of cube $\&$ cylinder prepared during the casting of beam and tested the same during testing and stressing of beam. The CFRP bar material was supplied by Dextra PVT Ltd Honghong, China. The $9.5 \mathrm{~mm}$ diameter of CFRP bar in an area $71.3 \mathrm{~mm}^{2}$ was used as prestress-

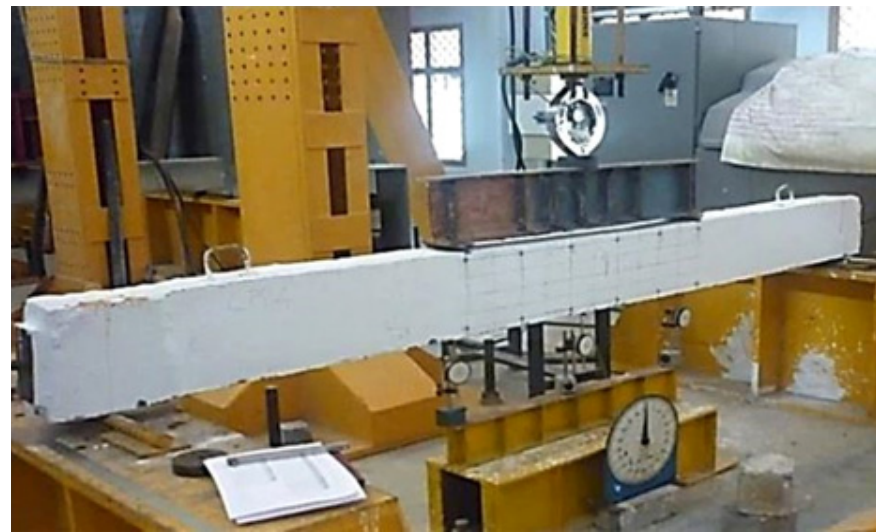

Fig. 5. Test Specimen and Setup

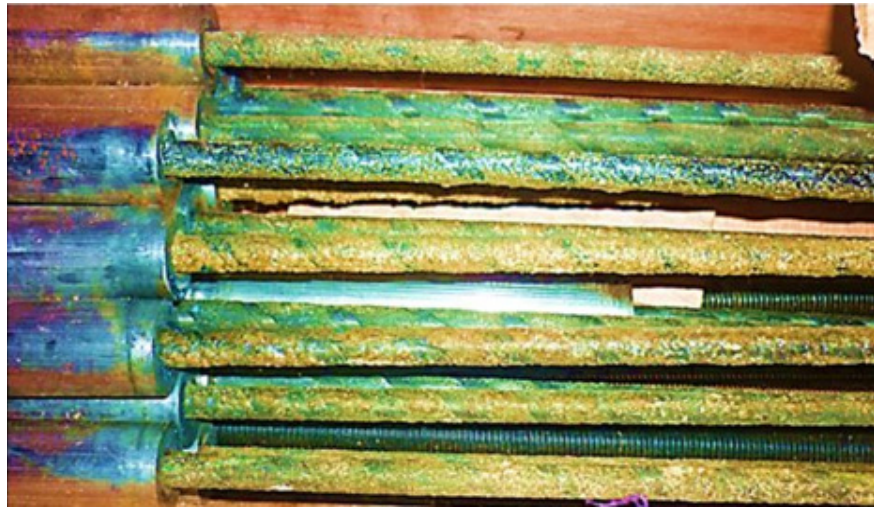

Fig. 6. CFRP Tendon with Splice Coupler

ing bar. The property of CFRP material as provided in Table 2. Both ends of CFRP bars are connected with splicer as shown in Fig. 6 to protect the surface of bar during stressing. Non-pretensioned steel reinforcement properties also included in Table 2.

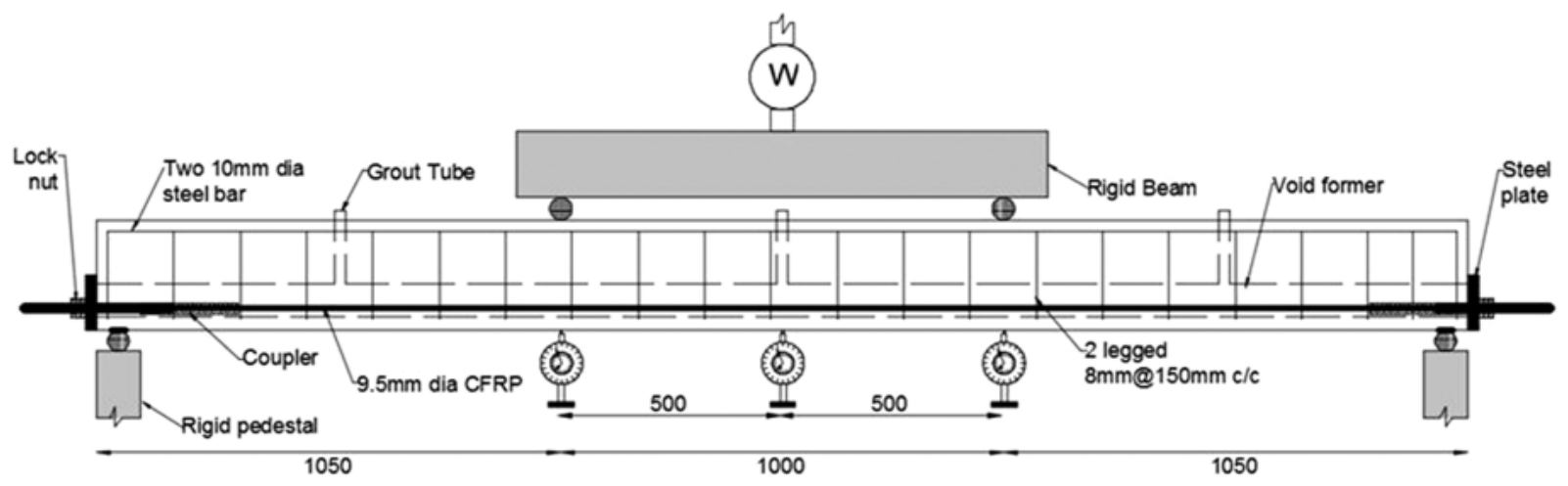

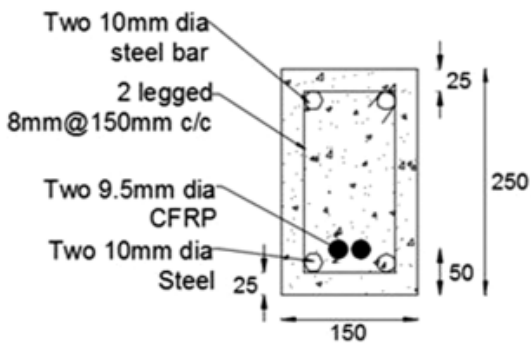

CPB1-2H-0.63

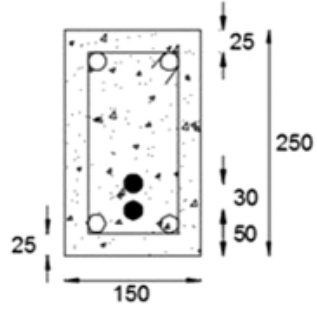

CPB2-2V-0.52

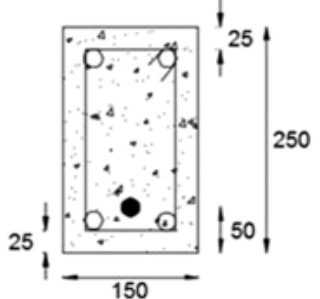

CPB3-1H-0.37

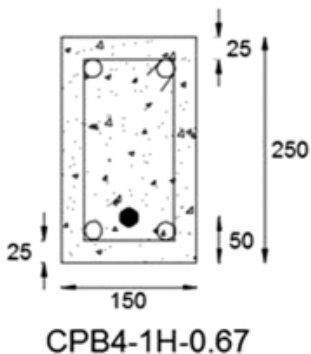

CPB4-1H-0.67

Fig. 7. Beam Configurations - Experimental Works 


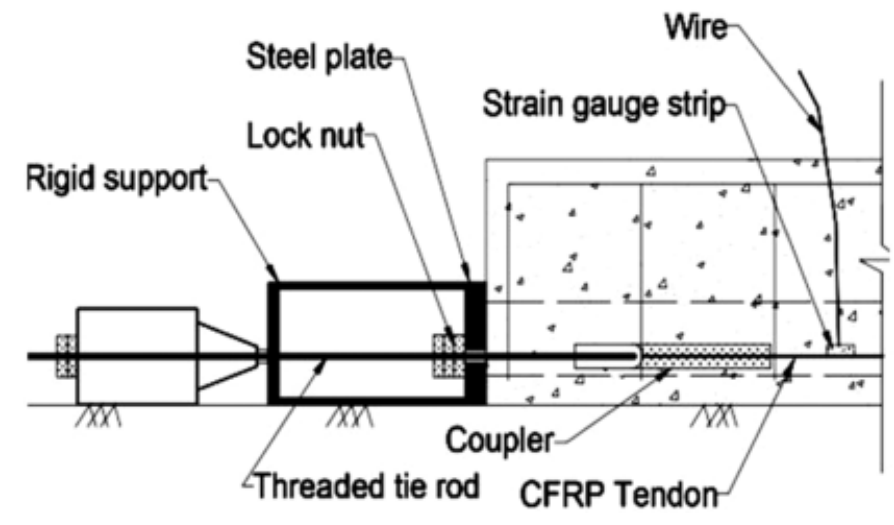

Fig. 8. Beam Anchorage system

Concrete Test Results

\begin{tabular}{|c|c|c|c|c|}
\hline \hline $\begin{array}{c}\text { Age in } \\
\text { days }\end{array}$ & $\begin{array}{c}\text { Average Cube } \\
\text { Compressive } \\
\text { Strength in MPa }\end{array}$ & $\begin{array}{c}\text { Average Tensile } \\
\text { Strength in } \\
\text { MPa }\end{array}$ & $\begin{array}{c}\text { Youngs } \\
\text { Modulus in } \\
\text { Mpa }\end{array}$ & Remarks \\
\hline 7 & 50.8 & 3.4 & $3.77 \times 10^{4}$ & \\
\hline 28 & 61.3 & 4.56 & $3.86 \times 10^{4}$ & \\
\hline
\end{tabular}

TABLE 2

Property of CFRP \& Steel Reinforcement

\begin{tabular}{|c|c|c|c|c|c|}
\hline \hline SL No & $\begin{array}{c}\text { Tensile } \\
\text { Strength } \\
\text { in MPa }\end{array}$ & $\begin{array}{c}\text { Youngs } \\
\text { Modulus } \\
\text { in Mpa }\end{array}$ & Strain & $\begin{array}{c}\text { Poisons } \\
\text { Ratio }\end{array}$ & Remarks \\
\hline 1 & 1896 & $1.24 \times 10^{5}$ & 0.0153 & 0.27 & $\begin{array}{c}\text { CFRP bar for } \\
\text { prestressing }\end{array}$ \\
\hline 2 & 500 & $2.00 \times 10^{5}$ & 0.0025 & 0.30 & $\begin{array}{c}\text { Steel } \\
\text { reinforcement }\end{array}$ \\
\hline
\end{tabular}

A special measure as proposed by Johnson BjorgvinSmari [10] is considered for the stressing and anchoring of prestressed beam as shown in Fig. 8. The target prestressing force is achieved by controlling the elongation of CFRP bar. Actual prestressing strain on CFRP bar was measured using strain gauge strip. The simply supported beam loaded with two points loading at an increment of $5 \mathrm{kN}$ up to first crack on beam and then it is reduced to $2.5 \mathrm{kN}$ during cracking stage. Deflection is recorded for each increment of loads. The degree of prestressing is varied for each beam to study the behavior of beam. Table 3 shows the prestressing force applied on bar and corresponding effective prestressing after deducting all the losses. Anchorage edge steel

plate is designed in such a way to transfer the stress uniformly on the side of member.

TABLE 3

Prestressing Force

\begin{tabular}{|c|c|c|c|c|c|}
\hline \multirow[b]{2}{*}{ Beam Type } & \multicolumn{3}{|c|}{ Prestressing force in $\mathrm{kN}$} & \multirow{2}{*}{$\begin{array}{c}\text { Partial } \\
\text { prestress- } \\
\text { ing ratio } \\
\text { (PPR) }\end{array}$} & \multirow[b]{2}{*}{$\begin{array}{c}\text { Re- } \\
\text { marks }\end{array}$} \\
\hline & $\begin{array}{l}\text { Initial } \\
\text { force }\end{array}$ & $\begin{array}{c}\text { Force due } \\
\text { to loss of } \\
\text { stressing }\end{array}$ & $\begin{array}{l}\text { Effective } \\
\text { stressing } \\
\text { force }\end{array}$ & & \\
\hline CPB1-2-H-0.63 & 189 & 19.27 & 169.73 & 0.775 & \\
\hline CPB2-2-V-0.52 & 158.5 & 17.37 & 141.13 & 0.775 & \\
\hline CPB3-1-H-0.37 & 57.9 & 7.44 & 50.46 & 0.633 & \\
\hline CPB4-1-H-0.68 & 100.6 & 91.66 & 9.06 & 0.633 & \\
\hline
\end{tabular}

\section{Results and discussion}

The flexural behavior of member shall be assessed based on the moment of resistance at initial crack stage, moment at steel yielding stage and final failure stage at ultimate load. The failure pattern shall be of either rupture failure of tendon or compression failure of concrete. The experimental test results of moment of resistance at first cracked stage is approximately same as theoretical calculations by ACI 440-4R [8] method as shown in Table 4, hence it shows the effectiveness of prestressing of CFRP bar and concrete strength of beam achieved as per design considerations. The failure of beam specimens were observed as rupture of CFRP tendon as shown in Fig. 10 which resembles the design consideration of tension controlled member. Load Vs Deflection curve as shown in Fig. 9 for the specimen of 37\% degree of prestressed beam CPB3 \& 68\% degree of prestressed beam. CPB4. High degree of prestressed beam provides better un-cracked moment of resistence than low degree of prestressed beam, however the ultimate moment of resistance are almost same for both cases. The failure loads at ultimate moment of resistance of beams are almost equal. It shows that varying degree of prestressing is not influencing the flexural strength of member. However the pattern of moment curvature is changing with respect to deformability and ductile behaviour of prestressed beam. The moment curvature as shown in Fig. 9 shall be idealized as trilinear curve when steel yields earlier than ultimate failure load of member. The point upto steel yield point, load vs deflection curve pattern resembles ACI 440-4R [8] \& Abdulrahman [9] method, beyond

TABLE 4

Experimental Results

\begin{tabular}{|c|c|c|c|c|c|c|c|c|c|}
\hline \multirow[t]{2}{*}{ Beam Type } & \multicolumn{2}{|c|}{$\begin{array}{l}\text { Moment of resistance } \\
\text { at cracking stage } \\
\text { Mcr }(\mathrm{kN}-\mathrm{m})\end{array}$} & \multicolumn{2}{|c|}{$\begin{array}{c}\text { Moment of resistance } \\
\text { at steel yielding stage } \\
\text { My }(\mathrm{kN}-\mathrm{m})\end{array}$} & \multicolumn{2}{|c|}{$\begin{array}{l}\text { Moment of resistance } \\
\text { at ultimate load } \\
\operatorname{Mr}(\mathbf{k N}-\mathrm{m})\end{array}$} & \multicolumn{2}{|c|}{$\begin{array}{l}\text { Mid Span deflection at } \\
\text { ultimate stage in mm }\end{array}$} & \multirow[t]{2}{*}{ Remark } \\
\hline & $\begin{array}{c}\text { ACI } \\
\text { method }\end{array}$ & $\begin{array}{c}\text { Experi- } \\
\text { mental }\end{array}$ & $\begin{array}{c}\text { ACI } \\
\text { method }\end{array}$ & $\begin{array}{c}\text { Experi- } \\
\text { mental }\end{array}$ & $\begin{array}{c}\text { ACI } \\
\text { method }\end{array}$ & $\begin{array}{c}\text { Experi- } \\
\text { mental }\end{array}$ & $\begin{array}{c}\text { Experi- } \\
\text { mental }\end{array}$ & $\begin{array}{c}\text { Proposed } \\
\text { Method }\end{array}$ & \\
\hline CFB1-2-H-0.63 & 25.87 & 29.2 & 55.11 & 51.2 & 65.52 & 69.00 & 41.20 & 38.98 & \\
\hline CFB2-2-V-0.52 & 21.12 & 23.6 & 47.02 & 44.6 & 62.04 & 57.30 & 30.40 & 32.63 & \\
\hline CFB3-1-H-0.37 & 11.96 & 14.40 & 28.42 & 24.2 & 41.43 & 38.20 & 32.80 & 33.60 & \\
\hline CFB4-1-H-0.68 & 16.31 & 19.0 & 34.75 & 29 & 40.12 & 38.10 & 22.80 & 24.53 & \\
\hline
\end{tabular}


which it is converged faster to reach the failure load of member. The cracked beam specimens are shown in Fig. 10 it shows that, more cracks propagation in the mid span region at bottom. Number of crack and crack width pattern resemble the Xue and Tan [11] experimental results. There are more numbers of cracks formed on beam specimen as compared to fully prestressed beam without non prestensioned steel. Further the crack spacing also closer due to the yield of non prestensioned steel reinforcement. The beam with lesser degree of prestressing has more number of cracks than high degree of prestressed beam.

Deflection of beam as shown in Table 4 shows that, the ultimate mid span deflection is less for the high degree of prestressed beam than low degree of prestressed beam. The pattern of deflection as shown in Fig. 9 shows that, the location of steel yield point is with respect to residual strain on CFRP bar after prestressing. Higher the residual strain higher the deformability of member and vice versa. The rate of convergence of deflection up to steel yield point depends on both CFRP bar and steel reinforcement strain parameter beyond which it will converge faster due to the contribution of less stiffness of CFRP bar. The rate of deflection convergence also depends on the residual strain on CFRP bar after steel yield point. Residual deflection after removal of load as shown in Fig. 9 is due to the plastic stage yielding of steel reinforcement.

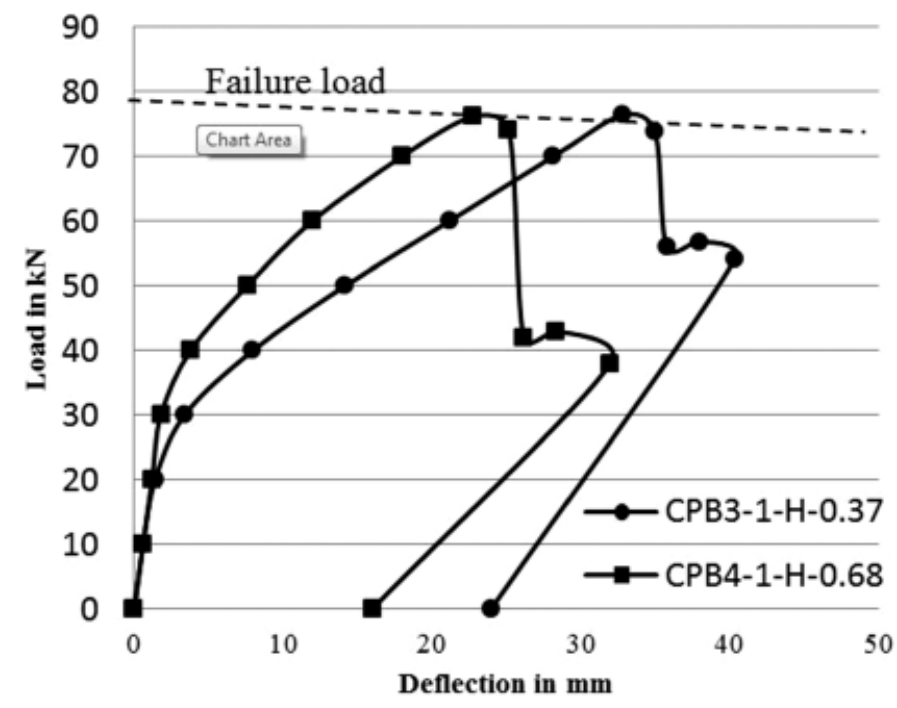

Fig. 9. Load vs Deflection CPB 3-1H-0.37 \& CPB4-1H-0.68

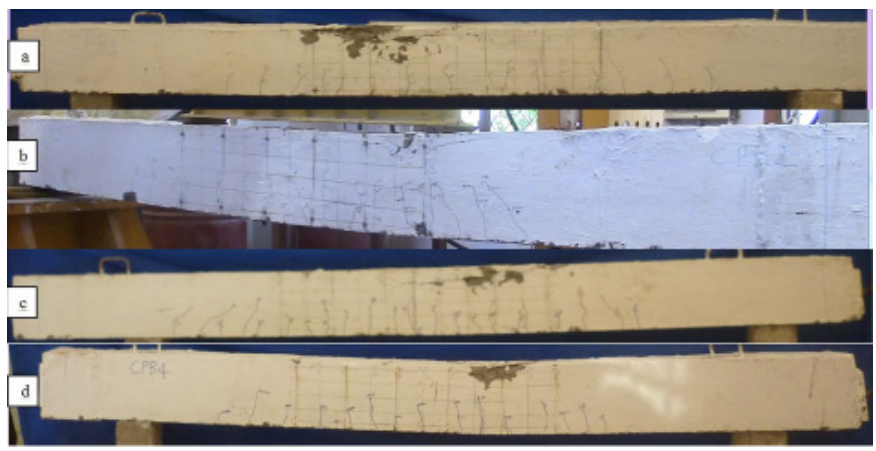

Fig. 10. Crack pattern of beam: (a) CPB1-2-H-0.63, (b) CPB2-2-V-0.52, (c) CPB3-1-H-0.37, (d) CPB4-1-H-0.68

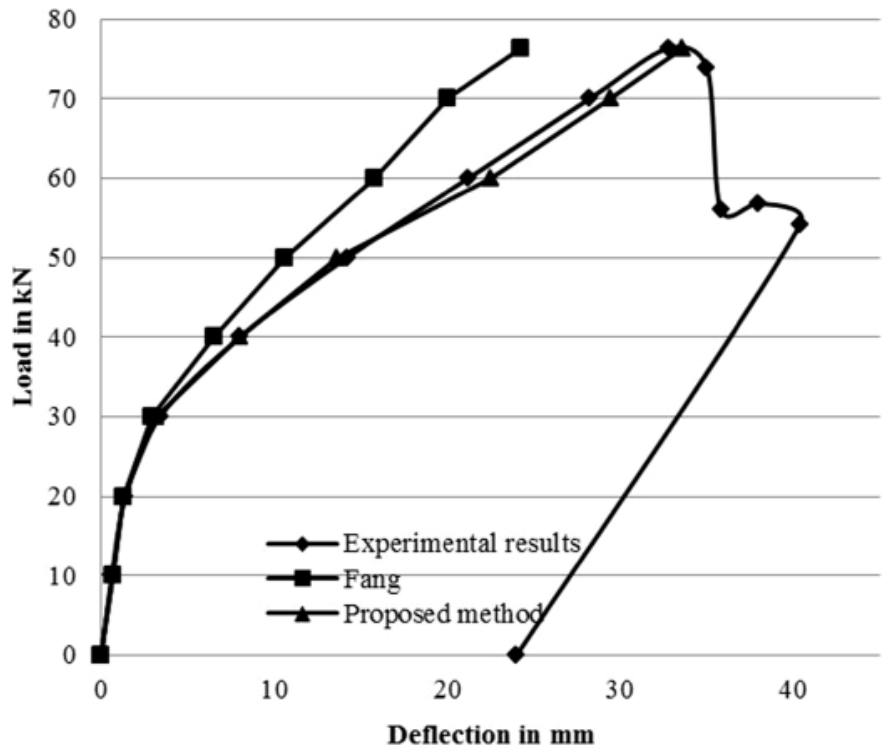

Fig. 11. Load Vs Deflection curve CPB3-1-H-0.37

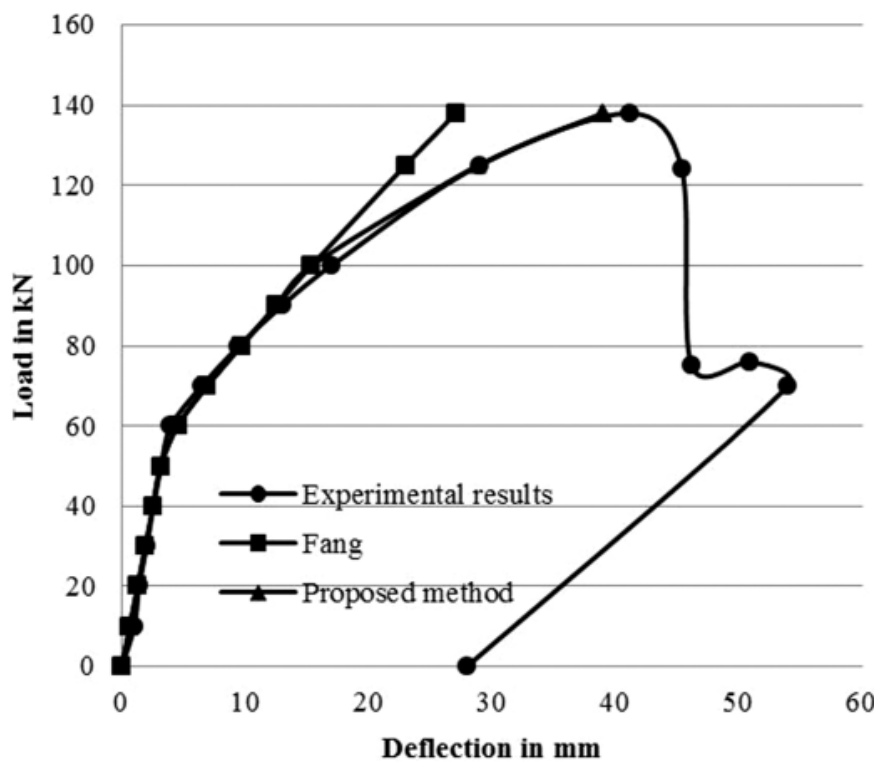

Fig. 12. Load Vs Deflection curve CPB1-2-H-0.63

\subsection{New Deflection Model}

Fang, et al. [2] idealized the deflection pattern as trilinear curve and derived moment curvature as per strain approach. The moment of inertia of member and neutral axis are at centroid up to first crack occurs on member and then the rate of reduction of moment of inertia $\left(I_{\text {eff } 1}\right)$ and centroid distance $\left(Y_{\text {eff } 1}\right)$ are as per equation (10) \& (13) up to the point of steel yielding. Further increase of load on member results in increase of stress on CFRP bar only. Steel reinforcement started to yield and carry strain without increase in stress on reinforcement. Equation (11) $\&$ (14) as proposed are used to calculate effective moment of inertia of member $\left(I_{e f f 2}\right) \&$ neutral axis shift $\left(Y_{\text {eff } 2}\right)$. ACI [8] and Abdulrahman method [9] adopted for calculation of rate of shift of moment of inertia and neutral axis distance. 
Ali and Hosein [12] stated that, the moment curvature curve varies slow and steadily up to steel yield point. Beyond yield point the material to be in plastic stage, and the moment of curvature $\Phi_{p}$ increases in a faster rate as shown in Fig. 13. The ratio of moment curvature $\left(\Phi_{y} / \Phi_{u}\right)$ depends on the partial prestressingratio of member. However the rate of increase of moment curvature beyond steel yield point is with respect to ductile behavior of steel reinforcement. The faster rate of shift of moment curvature leads to increase in deflection of member without increase in stress on member.

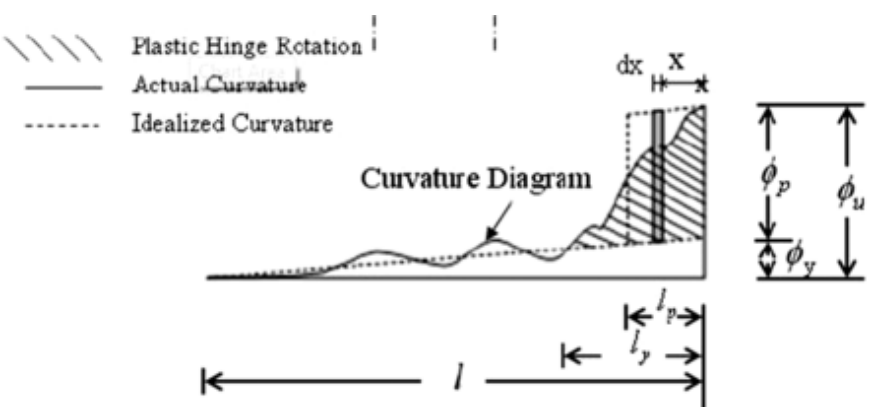

Fig. 13. Kheyroddin and HoseinNaderpour moment curvature of steel reinforced member

Hence a new correction factor $(\alpha)$ introduced for calculation of cracked moment of inertia considering the faster rate of shift of moment curvature. The correction factor $\alpha$ is multiplied with the stiffness of second moment of area for calculating the steel reinforcement the modified cracked moment of inertia shall be calculated by taking moment about neutral axis.

$$
\begin{aligned}
I_{c r}= & \frac{b Y_{c r}^{3}}{3}+m_{p} f_{p u} A_{p}\left(d_{p}-Y_{c r}\right)^{2}+ \\
& +\alpha m_{s} f_{y} A_{s t}\left(d_{s}-Y_{c r}\right)^{2}
\end{aligned}
$$

The value of correction factor $\alpha$ depends on the moment curvature ratio at first yield point of steel $\left(\Phi_{y}\right)$ and moment curvature at ultimate level $\left(\Phi_{u}\right)$. It shall be calculated by basic pure bending equations.

$$
\Phi_{y}=\frac{M_{y}}{E I_{y}}=\frac{\varepsilon_{s}}{\left(d_{s}-Y_{y}\right)}=\frac{\varepsilon_{p 1}}{\left(d_{p}-Y_{y}\right)}
$$

Where $\varepsilon_{p 1}$ is a strain on CFRP bar at steel first yield point and it shall be calculated from Fig. 2 member strain diagram by equating similar triangle.

$$
\varepsilon_{p 1}=\frac{\varepsilon_{s}\left(d_{p}-Y_{y}\right)}{\left(d_{s}-Y_{y}\right)}
$$

The moment curvature at ultimate stage calculated from Fig. 3 member strain diagram by equating similar triangle.

$$
\Phi_{u}=\frac{M_{u}}{E I_{c r}}=\frac{\varepsilon_{f}}{\left(d_{p}-Y_{c r}\right)}
$$

Where $M_{y}$ moment of resistance at steel yield point and $M_{u}$ moment of resistance at ultimate stage.

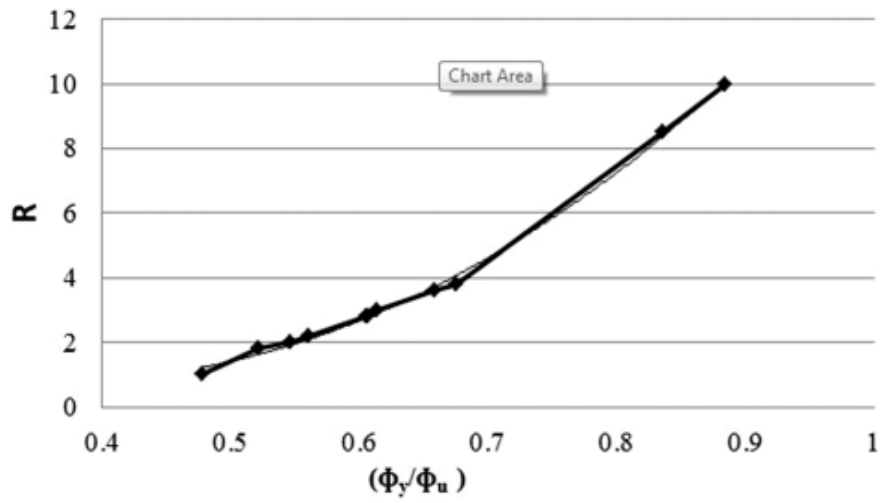

Fig. 14. Power coefficient ' $R$ ' for the correction factor

The correction factor $\alpha$ also considering the faster rate of moment curvature shift after steel yield point by powering the rate of shift of moment curvature ratio.

$$
\begin{gathered}
\alpha=\left(\frac{\Phi_{y}}{\Phi_{u}}\right)^{R} \\
\alpha=\left(\frac{\Phi_{y}}{\Phi_{u}}\right)^{R}=\frac{\varepsilon_{s}\left(d_{p}-Y_{c r}\right)^{R}}{\varepsilon_{f}\left(d_{s}-Y_{y}\right)^{R}}
\end{gathered}
$$

Naaman and Jeong [13] stated that the convergence of load deflection curve depends on the residual strain on CFRP bar after decompressed strain and after first yield point of steel reinforcement $\left(\varepsilon_{r}=\varepsilon_{p u}-\varepsilon_{p e}-\varepsilon_{p 1}\right)$. Lower residual strain $\left(\varepsilon_{r}\right)$ leads to higher ratio of $\left(\Phi_{y} / \Phi_{u}\right)$, hence the higher power coefficient ' $R$ ' introduced as shown in Fig. 14 to faster the convergence of deflection towards failure load. The ultimate mid span deflection of this member is less due to its low deformability nature. The ultimate deflection value of beam member CPB 4 as mentioned in Table 4 shows the ultimate mid deflection value of $22.8 \mathrm{~mm}$ as less as compared to high deformability beam CPB 3 deflection value of $32.8 \mathrm{~mm}$.

Similarly the higher the residual strain $\left(\varepsilon_{r}\right)$ leads to lower the ratio of $\Phi_{y} / \Phi_{u}$ hence the lower the power coefficient ' $\mathrm{R}$ ' introduced as shown in Fig. 14 to slower the convergence of deflection towards failure load. The ultimate mid span deflection of this member is higher due to its high deformability behaviour.

The value of power co-efficient ' $R$ ' shall be calculated by the below equation as arrived by plotting tread line to the curve as shown in Fig. 14.

$$
R=34.53\left(\frac{\Phi_{y}}{\Phi_{u}}\right)^{2}-25.43\left(\frac{\Phi_{y}}{\Phi_{u}}\right)+5.5
$$

Yu and Jiongfeng [14] stated that, the value of $I_{\text {eff } 2}$ converges faster due to the less stiffness of CFRP bar and due to its deformability behavior, hence the ACI 440-4R method modified considering its deformability behaviour.

$$
I_{\text {eff } 2}=\left(\frac{M_{y}}{M_{a}}\right)^{5} I_{y}+\left(1-\left(\frac{M_{y}}{M_{a}}\right)^{5}\right) I_{c r}
$$


The load vs deflection experimental results are compared with Fang and Proposed method. From Fig. 11 \& 12 it clear that, the proposed method is converging to the experimental results as compared to Fang method. Higher the residual strain, higher the difference in deflection value by frank method.

\section{Conclusion and recommendations}

The deflection calculation for the partially prestressed beam with non prestensioned steel reinforcement compared with frank and ACI methods. Frank trilinear idealization of deflection considered for the development of new deflection model. Frank model is not converging to the experimental results due to the faster rate of shift of moment curvature during plastic yield of steel reinforcement and deformability behavior of CFRP bar. New deflection model is developed based on the effect of residual strain $\left(\varepsilon_{r}\right)$ on CFRP bar after decompressed strain and after first yield point of steel reinforcement. The following conclusions are arrived based on the analytical and experimental study in this article.

- The tri-linear load deflection occurs due to the presence of non-pretensioned steel and which helps to improve the yielding behaviour of member.

- The convergence of deflection of member after steel first yield point converging with respect to CFRP deformability and steel ductility behaviour.

- Higher the deflection on similar PPR ratio member will occurs when higher the residual strain $\left(\varepsilon_{r}\right)$ on CFRP bar available to deform and vice versa .

- $\quad$ A correction factor $(\alpha)$ proposed for calculation of deflection beyond steel first yield point based on the effect of residual strain $\left(\varepsilon_{r}\right)$ on CFRP bar.

- $\quad$ ACI 440-4R recommendation of moment of inertia after steel yield point $\left(I_{e f f 2}\right)$ is modified to higher power curve as shown in equation (22) considering the higher convergence behaviour of beam with respect to deformability behaviour of CFRP prestressed beam.

Detailed experimental and numerical studies required to study the serviceability behavior of beam considering more number of experimental test samples to validate the proposed model.

\section{Acknowledgments}

The authors are grateful to the following:

Mr. R. Bala Subramanian, Mr. Pierre Hofmann and the Management of Dextra Building Products (Guang Dong) Co., Ltd, Guangzhou China for the sponsor of CFRP material to carryout experimental works. Dr.G. Mohan Kumar, Annamalai University for his technical guidence to carryout experimental works.

Dr.S.Suchithra_Assistant Professor (Sr Grade), Kongu Engineering college for preparing this article.

Dr.M. Suchetha for her support to carryout the research works.

\section{REFERENCES}

[1] C.W. Dolan, P.E. Chad, R. Burke, PCI Journal. 46, 76-87 (2001).

[2] Fang Zhi, Gong chang, Yang jian, TI. Campbell, Journal of Cent. South Univ. technol, Springer Journal. 16, 495-502 (2009).

[3] Shunji Inomata, PCI Journal. 1, 100-116 (1982).

[4] D.E. Branson, ACI Journal. 65, 730-742 (1968).

[5] Natalie sami rizkalla, Partial bonding and partial prestressing using stainless steel reinforcement for membersprestressed with FRP in: Master of science thesis, Queen university, Canada, 2000.

[6] D.E. Branson, H. Trost, PCI Journal. 1, 62-67 (1982).

[7] M. Tadros, A. Ghali, A. Meyer, PCI Journal. 30, 114-141 (1985).

[8] ACI 440.4R-04 (American Concrete Institute) 2004. Reapproved 2011. Prestressing concrete structures with FRP Tendons.

[9] A. Abdelrahman, S. Rizkalla, ACI Journal. 94, 447-457 (1997).

[10] Bjorgvin Smari Johnson, Prestressed BFRP tendons in concrete beam in: Master of science thesis, Hoskolinn reukjavik university, Iceland, 2011.

[11] Xue Weichen, Yuan Tan, Proce. of the 6th Int. Conf. on Compo. in Civil Engg. Rome, Italy, (2012).

[12] Ali Kheyroddin, Hosein Naderpour, Int. journal of civil Engg. 5,30-47 (2007).

[13] A.E. Naaman, SM. Jeong, Non-metalic reinf. for concrete structure. 1, 379-386, (1995).

[14] Yu Deng, Jiongfeng Liang, Adv. material research. 168, 21822185, (2011). 